\title{
A PRACTICAL ALGORITHM FOR SIMULATION OF TRANSIENT PERFORMANCE OF CHOPPER-CONTROLLED R-L AND DC DRIVE LOADS
}

\author{
Mehmet Akbaba and Orhan Özhan \\ Department of Electrical and Electronics Engineering, College of Engineering, \\ University of Bahrain, P.O. Box 33547, Isa Town, Bahrain \\ akbaba@eng.uob.bh
}

\begin{abstract}
This paper presents a practical algorithm for obtaining transient response of chopper-controlled active and passive loads. Core algorithm given for simulating transient response of chopper-controlled R-L load is extended to chopper-controlled DC drive, covering both the continuous and discontinuous current modes of operation. Although chopper-controlled loads are taken as case studies, with a little effort the core algorithm can be readily extended to handle the transient response of the other system which manifests periodic discontinuous forcing functions of different types. Transient current and speed responses of chopper-controlled DC drive, which are obtained from application of the proposed algorithm are compared with their counterparts obtained from detailed numerical solution of the state-space model of the drive using fourthorder Runge-Kutta method, and the advantages of proposed algorithm are discussed.
\end{abstract}

Keywords- Transient response, chopper-controlled loads, Runge-Kutta method.

\section{INTRODUCTION}

Chopper-controlled loads such as inductive loads (R-L) and DC drive loads are commonly used in industry. Often it is desirable to analyze their transient performance. With widespread availability of personal computers and numerical software [1-4], it is fairly easy to accomplish the task. However, practicing engineers often hesitate to be involved in using sophisticated numerical techniques. Instead they are more inclined to use simple and direct algorithms, which they can easily program in any high-level programming language. Occasionally instead of providing practical algorithms that are very easy to implement, the matter is further complicated unnecessarily by the like of the method proposed in [5]. Although the method given in [5] is applied to a simple R-L circuit, it involves a very complicated and time-consuming process, which is absolutely unnecessary.

In this paper a very simple and practical algorithm is proposed, which produces same results as obtained in [5]. The algorithm is further extended for computing the performance of a DC drive. It would be extremely complicated if any attempt is made to extend the technique given in [5] for accomplishing the same task. Algorithm proposed in this paper is also capable of predicting the transient, as well as the steady-state performance of chopper-controlled R-L and DC drive loads in a very simple and yet a very accurate way, which is believed to be very useful for a practicing engineer. Reliability and accuracy of the algorithm will be illustrated with examples. 


\section{PROPOSED ALGORITHM AND ITS APPLICATIONS}

The proposed algorithm first will be presented for R-L load and then it will be extend to DC drives.

\subsection{R-L Load Case}

Schematic diagram of a chopper-controlled R-L load is given in Figure 1. Reference [5] is misleading as no reference is made to the freewheeling diode path throughout the paper.

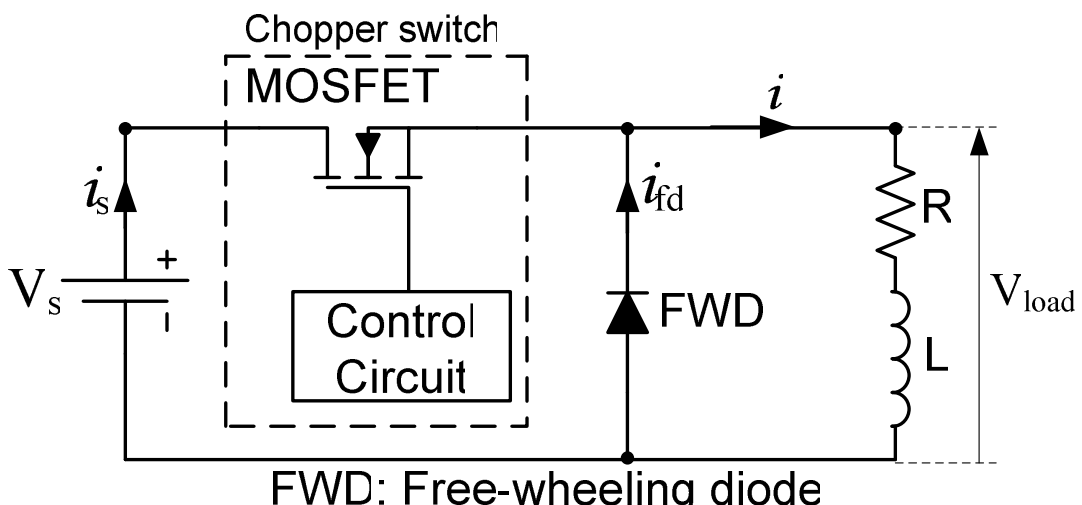

Figure 1: Chopper-controlled R-L load

When chopper is on, the equation governing the operation of an R-L load is

$V_{\text {load }}\left(t_{a}\right)=\mathrm{V}_{\mathrm{s}}=\mathrm{R} i\left(t_{a}\right)+\mathrm{L} \frac{\mathrm{d} i\left(t_{a}\right)}{\mathrm{d} t_{\mathrm{a}}} \quad\left(\right.$ for $\left.0 \leq \mathrm{t}_{\mathrm{a}} \leq \mathrm{DT}\right) \quad$ and $\left(i(t)=i\left(t_{a}\right)\right)$

where ' $t$ ' ' is defined as the elapsed time during on period of a cycle defined only when $0 \leq \mathrm{t}_{\mathrm{a}} \leq \mathrm{DT}$ and it is initialized to zero at the end of each on period of the chopper when $\mathrm{t}_{\mathrm{a}}=\mathrm{DT}$. load is

During off period of the chopper the equation governing the operation of an R-L

$V_{\text {load }}\left(t_{b}\right)=0=\mathrm{R} i\left(t_{b}\right)+\mathrm{L} \frac{\mathrm{d} i\left(t_{b}\right)}{\mathrm{d} t_{\mathrm{b}}} \quad\left(\right.$ for $\left.0 \leq \mathrm{t}_{\mathrm{b}} \leq(1-\mathrm{D}) \mathrm{T}\right) \quad$ and $\left(i(t)=i\left(t_{b}\right)\right)$

where ' $t_{\mathrm{b}}$ ' is defined as the elapsed time during off period of a cycle only and it is reset to zero at the end of each off period of the chopper, i.e., when $t_{\mathrm{b}}=(1-\mathrm{D}) \mathrm{T}$. The voltage 
drop across the free-wheeling diode is neglected. Solution of Equation (1) is

$$
i(t)=\frac{\mathrm{V}_{\mathrm{s}}}{\mathrm{R}}\left[1-\exp \left(-\frac{t_{\mathrm{a}}}{\tau}\right)\right]+\mathrm{I}_{1} \exp \left(-\frac{t_{\mathrm{a}}}{\tau}\right) \quad\left(\text { for } 0 \leq \mathrm{t}_{\mathrm{a}} \leq \mathrm{DT}\right)
$$

And solution of Equation (2) is

$$
i(t)=\mathrm{I}_{2} \exp \left(-\frac{t_{\mathrm{b}}}{\tau}\right) \quad\left(\text { for } 0 \leq \mathrm{t}_{\mathrm{b}} \leq(1-\mathrm{D}) \mathrm{T}\right)
$$

where $I_{1}$ and $I_{2}$ are minimum and maximum values of the current during each cycle as shown in Figures 2 and 3, and $\tau=L / R$ is the time constant of the circuit. In steady state operation formulation of $I_{1}$ and $I_{2}$ are well known and can be obtained in power electronics books $[6,7]$. But in transient operation they are not known and they need to be calculated at each cycle separately. It will be shown below that in the proposed algorithm calculation of $I_{1}$ and $I_{2}$ is a simple matter, as they are the currents at the beginning and end of the on and off periods of the chopper, as shown in Figures 2 and 3. Calculation starts with $\mathrm{I}_{1}=0$ and $\mathrm{I}_{2}=0$. Then $\mathrm{I}_{2}$ is obtained as the current computed the end of chopper on period when $t_{c}=t_{a}=\mathrm{DT}$, i.e., $\mathrm{I}_{2}=i\left(t_{a}=\mathrm{DT}\right)$. As can be seen from Equation (4), only $\mathrm{I}_{2}$ is required for calculation of the current during $t_{c}=\mathrm{DT}+t_{b}$, which has the same meaning as $0 \leq t_{b} \leq(1-\mathrm{D}) \mathrm{T}$. Then $\mathrm{I}_{1}$ is obtained as the current computed at the end of chopper off period when $t_{c}=\mathrm{T}$, i.e., when $t_{b}=(1-\mathrm{D}) \mathrm{T}$ (given that $t_{c}=t_{a}+t_{b}$ and $\left.t_{b}=(1-\mathrm{D}) \mathrm{T}\right)$. It can be seen from Equation (3) that only $\mathrm{I}_{1}$ is required for calculation of the current during $0 \leq t_{a} \leq \mathrm{DT}$ and the current at the end of this period will give $\mathrm{I}_{2}$ again. Therefore $I_{1}$ and $I_{2}$ are updated at the end of each on and off periods of the chopper, without loss of accuracy.

In the proposed algorithm the sum of $t_{a}$ and $t_{b}$ is defined as $\boldsymbol{t}_{c}\left(t_{c}=t_{a}+t_{b}\right)$ which is the elapsed time during each complete cycle of the chopper and it is initialized to zero at the end of each cycle, i.e., when $t_{c}=\mathrm{T}$. The proposed algorithm is given below:

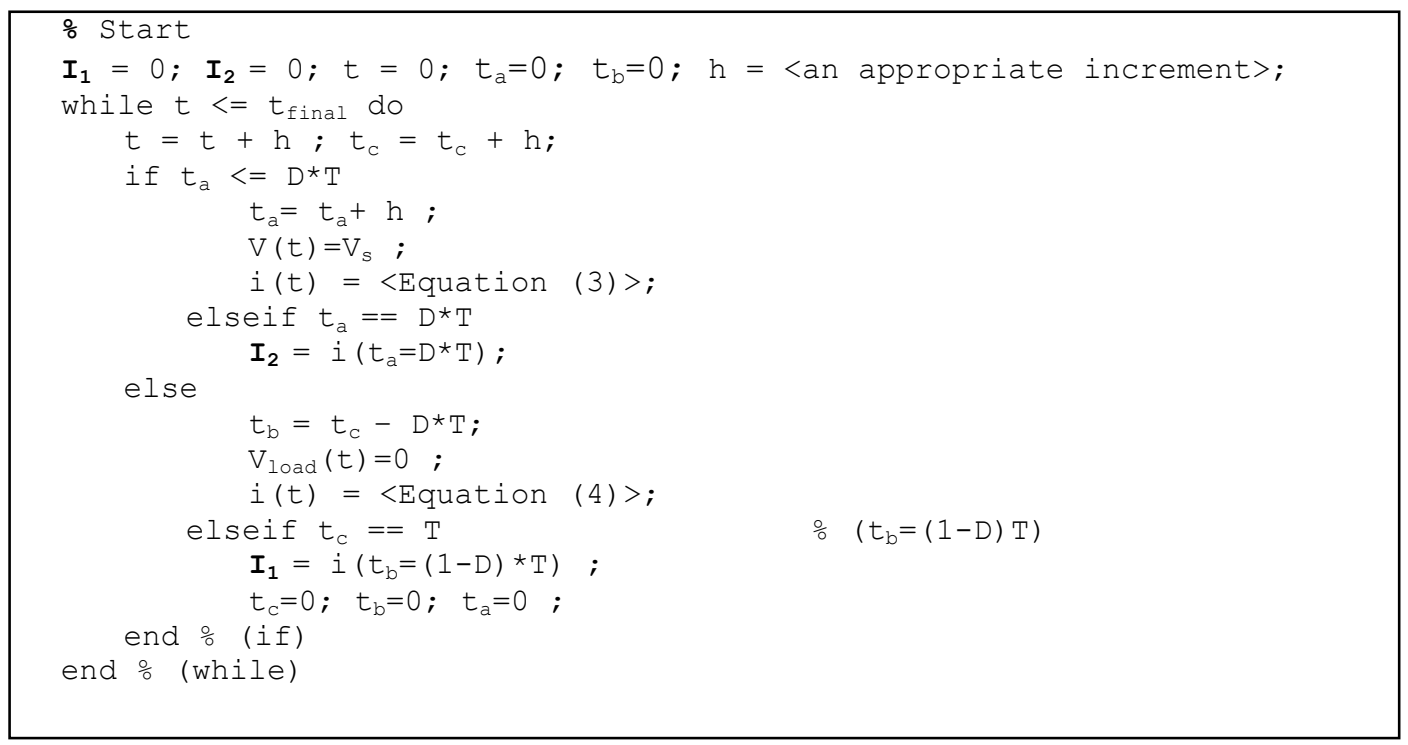


The key elements in calculating the transient current are $\mathrm{I}_{1}$ and $\mathrm{I}_{2}$ and it is clearly seen that given algorithm calculates their values in a very simple way. To test the proposed algorithm and compare the results with the results of reference [5], the circuit parameters given in [5] have been used. $\left(\mathrm{R}=4 \Omega, \mathrm{L}=0.06 \mathrm{H}, \mathrm{T}=0.005 \mathrm{sec}, \mathrm{V}_{\mathrm{s}}=200\right.$ $\mathrm{V}, \mathrm{D}=0.5$ ). The proposed algorithm and the method given in [5] are programmed in MATLAB. Computed transient and steady state responses are illustrated in Figures 2 and 3 respectively. Also the direct numerical solution of the main state space equations (1) and (2), using fourth-order Runge-Kutta method [8] is included in Figures 2 and 3. It is evident from these figures that the results obtained from the proposed algorithm in this paper matches perfectly with the detailed numerical solution of the state differential equation of the circuit using Runge-Kutta fourth-order method [8]. Results obtained using the proposed algorithm exactly match those obtained from the application of the method given in [5], i.e., the results are completely superimposed and they can not be identified from each other in these figures. But the proposed algorithm is much superior to the method given in [5], as it is much simpler to understand and implement, with much less effort and much less computing time. The computing time of the proposed algorithm is shorter by a factor of 3.6.
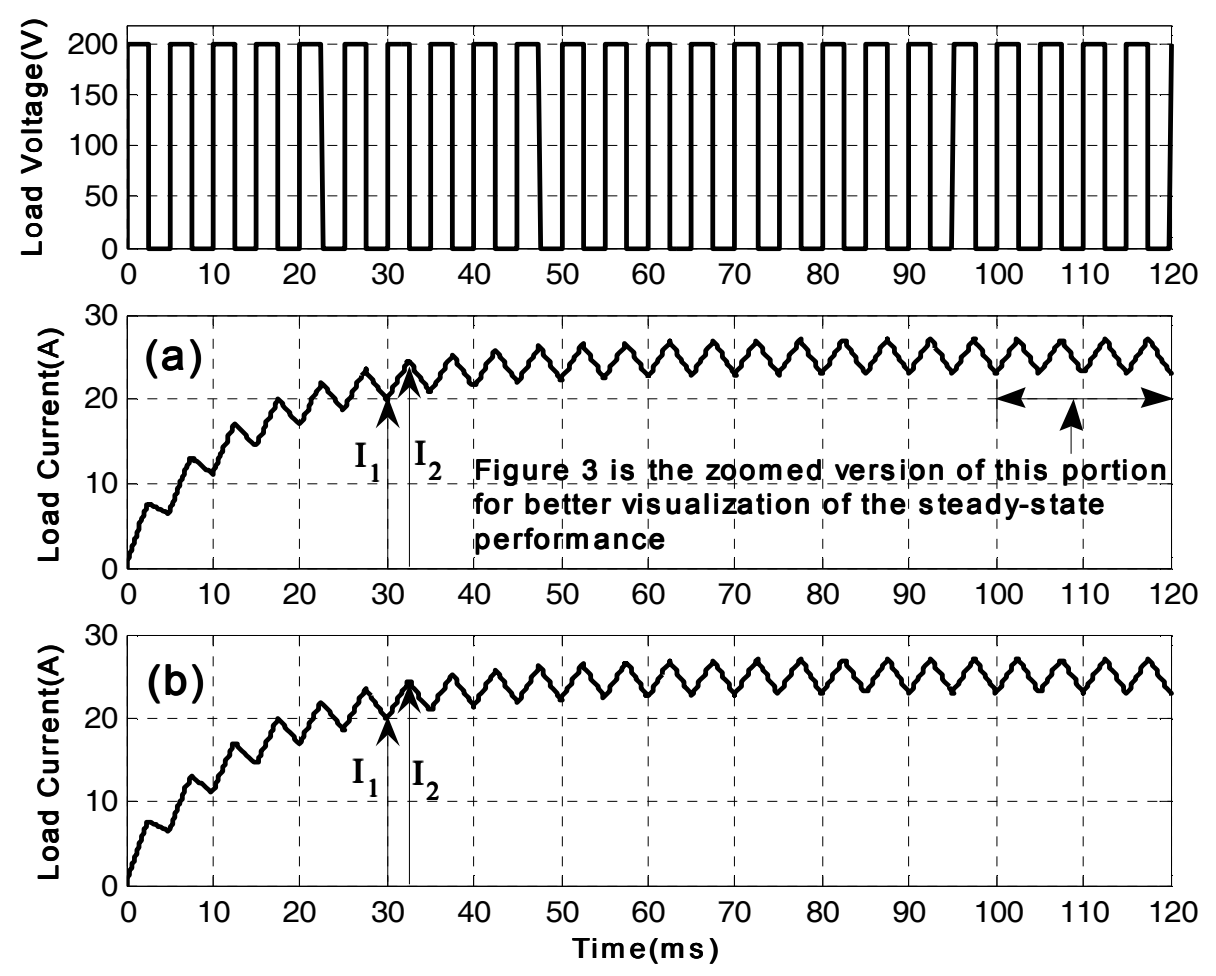

Figure 2: Transient response of given R-L circuit. (a) Load current obtained using proposed algorithm (b) Load current obtained using Runge-Kutta method. 

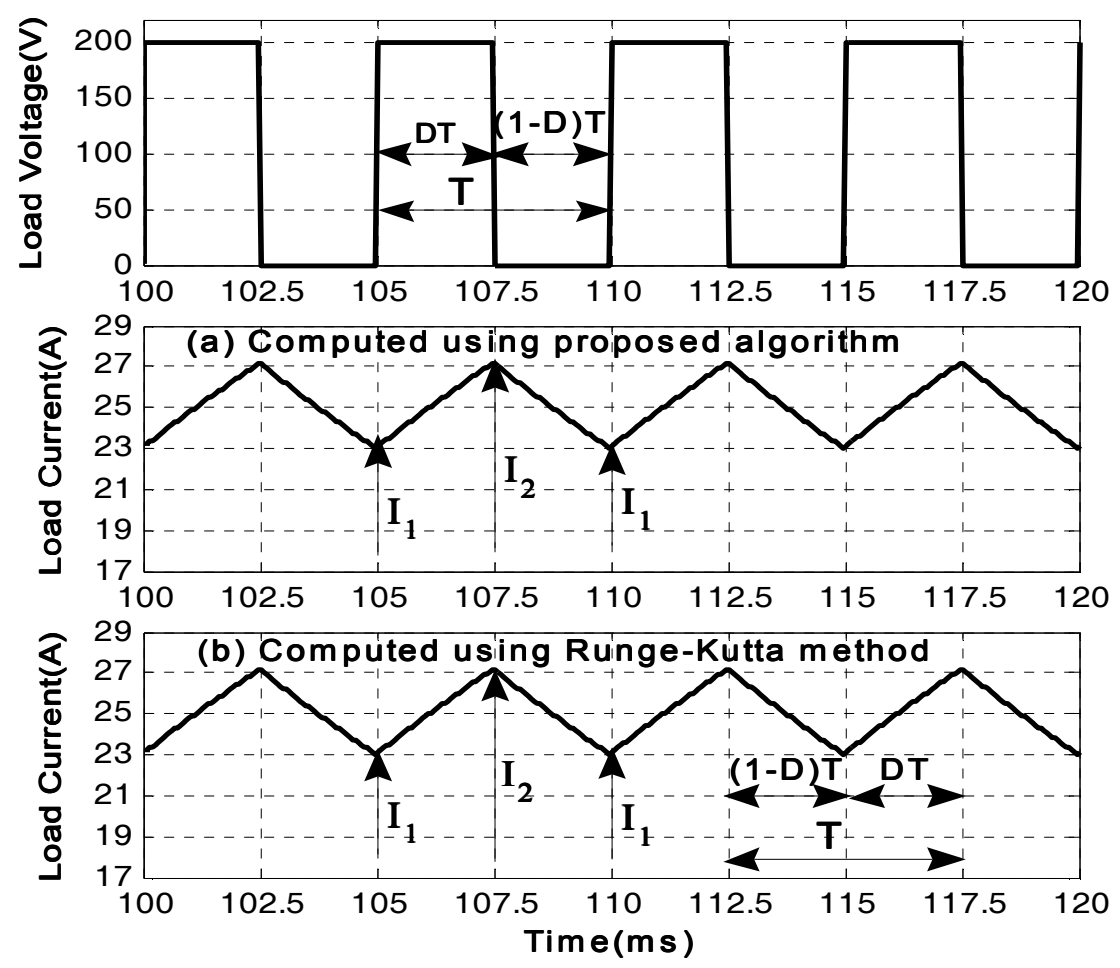

Figure 3: Steady-state response of given R-L circuit. (a) Load current obtained using proposed algorithm. (b) Load current obtained using Runge-Kutta method.

The steady state performance of the circuit is given in Figure 3. This figure is obtained as the zoomed part of the extended time transient solution where solution is completely converged to its steady state regime, as shown in Figure 2. It is evident from this figure that there is excellent match between the results obtained from the proposed algorithm and the detailed solution obtained from Runge-Kutta fourth-order method.

Figure 3 also clarifies the meanings of various notations symbols used in the proposed algorithm.

\subsection{Chopper-Controlled DC Drive Case}

Algorithm given above can be easily extended to handle response of any circuit subject to a periodic forcing function. Here the algorithm given above will be extended to obtain transient response of a chopper-controlled DC motor driving a fan type load, such as a water pump. Schematic diagram of a chopper-controlled separately excited DC motor driving a fan type load is given in Figure 4.

The torque-speed characteristic of a fan type load is given as [9]:

$$
\mathrm{T}_{\mathrm{L}}=\mathrm{k}_{\mathrm{L}} \omega(\mathrm{t})^{2}
$$




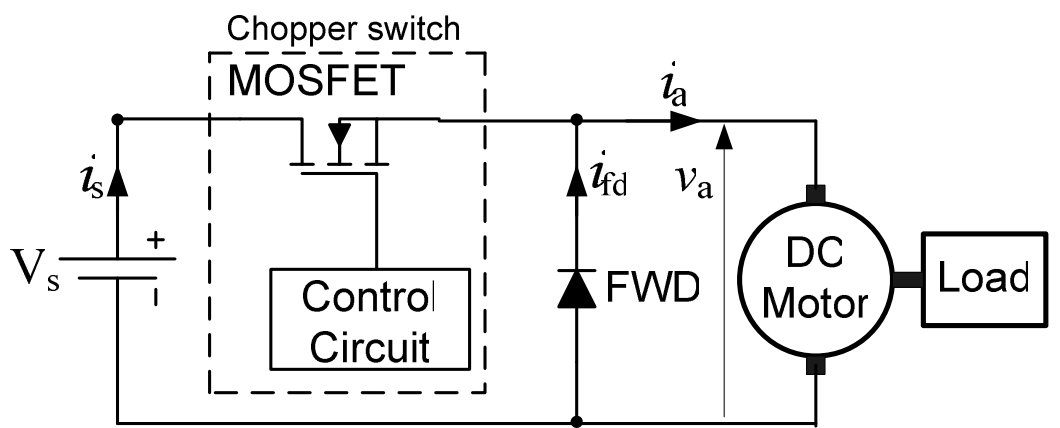

FWD: Free-wheeling diode

Figure 4: Chopper-controlled DC drive.

During chopper on period, the voltage equation governing the operation of the drive is

$v_{\mathrm{a}}\left(t_{a}\right)=\mathrm{V}_{\mathrm{s}}=\mathrm{R}_{\mathrm{a}} i_{\mathrm{a}}\left(t_{a}\right)+\mathrm{L}_{\mathrm{a}} \frac{\mathrm{d} i_{\mathrm{a}}\left(t_{a}\right)}{\mathrm{d} t_{\mathrm{a}}}+\mathrm{k} \Phi \omega(t) \quad\left(\right.$ for $\left.0 \leq \mathrm{t}_{\mathrm{a}} \leq \mathrm{DT}\right)$

(and $i_{a}(t)=i_{a}\left(t_{a}\right)$ )

During chopper off period the voltage equation governing the operation of the drive is

$v_{\mathrm{a}}\left(t_{b}\right)=0=\mathrm{R}_{\mathrm{a}} i_{\mathrm{a}}\left(t_{b}\right)+\mathrm{L}_{\mathrm{a}} \frac{\mathrm{d} i_{\mathrm{a}}\left(t_{b}\right)}{\mathrm{d} t_{b}}+\mathrm{k} \Phi \omega(t) \quad\left(\right.$ for $\left.0 \leq \mathrm{t}_{\mathrm{b}} \leq(1-\mathrm{D}) \mathrm{T}\right)$

(and $\left.i_{a}(t)=i_{a}\left(t_{b}\right)\right)$

Equation of the motion of the drive during both on and off periods of the chopper is

$$
\mathrm{J} \frac{\mathrm{d} \omega(\mathrm{t})}{\mathrm{dt}}=\mathrm{k} \Phi i_{a}(t)-\mathrm{k}_{\mathrm{L}} \omega(t)^{2}
$$

' $t_{\mathrm{a}}$ ' and ' $t_{\mathrm{b}}$ ' appearing in equations (6) and (7) have the same definitions and meanings as described earlier.

Utilizing the minimum and maximum values of armature current during each individual cycle, then solution of Equation (6) (during on period) is

$$
i_{a}(\mathrm{t})=\left(\frac{\mathrm{V}_{\mathrm{s}}-\mathrm{k} \Phi \omega_{\mathrm{n}}(t)}{\mathrm{R}_{\mathrm{a}}}\right)\left(1-\exp \left(-\mathrm{t}_{\mathrm{a}} / \tau_{\mathrm{m}}\right)\right)+\mathrm{I}_{1} \exp \left(-\mathrm{t}_{\mathrm{a}} / \tau_{\mathrm{m}}\right) \quad\left(\text { for } 0 \leq \mathrm{t}_{\mathrm{a}} \leq \mathrm{DT}\right)
$$

And solution of equation (7) (during off period of the chopper) is 
$i_{a}(\mathrm{t})=\mathrm{I}_{2} \exp \left(-\mathrm{t}_{\mathrm{b}} / \tau_{\mathrm{m}}\right)-\left(\frac{\mathrm{k} \Phi \omega_{\mathrm{n}}(t)}{\mathrm{R}_{\mathrm{a}}}\right)\left(1-\exp \left(-\mathrm{t}_{\mathrm{b}} / \tau_{\mathrm{m}}\right)\right) \quad\left(\right.$ for $\left.0 \leq \mathrm{t}_{\mathrm{b}} \leq(1-\mathrm{D}) \mathrm{T}\right)$

Since mechanical transients are much slower than electrical transients, the solution of Equation (8), for both on and off periods of the chopper can be formulated as given below:

$\omega_{\mathrm{n}}(t)=\omega_{\mathrm{n}-1}+(\mathrm{h} / \mathrm{J})\left(\mathrm{k} \Phi i_{\mathrm{a}(\mathrm{n}-1)}-\mathrm{k}_{\mathrm{L}} \omega_{\mathrm{n}-1}^{2}\right) \quad\left(\omega(t)=\omega_{\mathrm{n}}(t)\right)$

It is needless to mention that the current and speed are updated after each computation step. $\mathrm{I}_{1}$ and $\mathrm{I}_{2}$, which are key parameters in calculation of the drive performance, are updated at the end of each on and off periods of the chopper in the same manner as described earlier for R-L circuit.

The core algorithm given for R-L circuit is extended to cover DC drive equations that are described above and the resulting algorithm is given below.
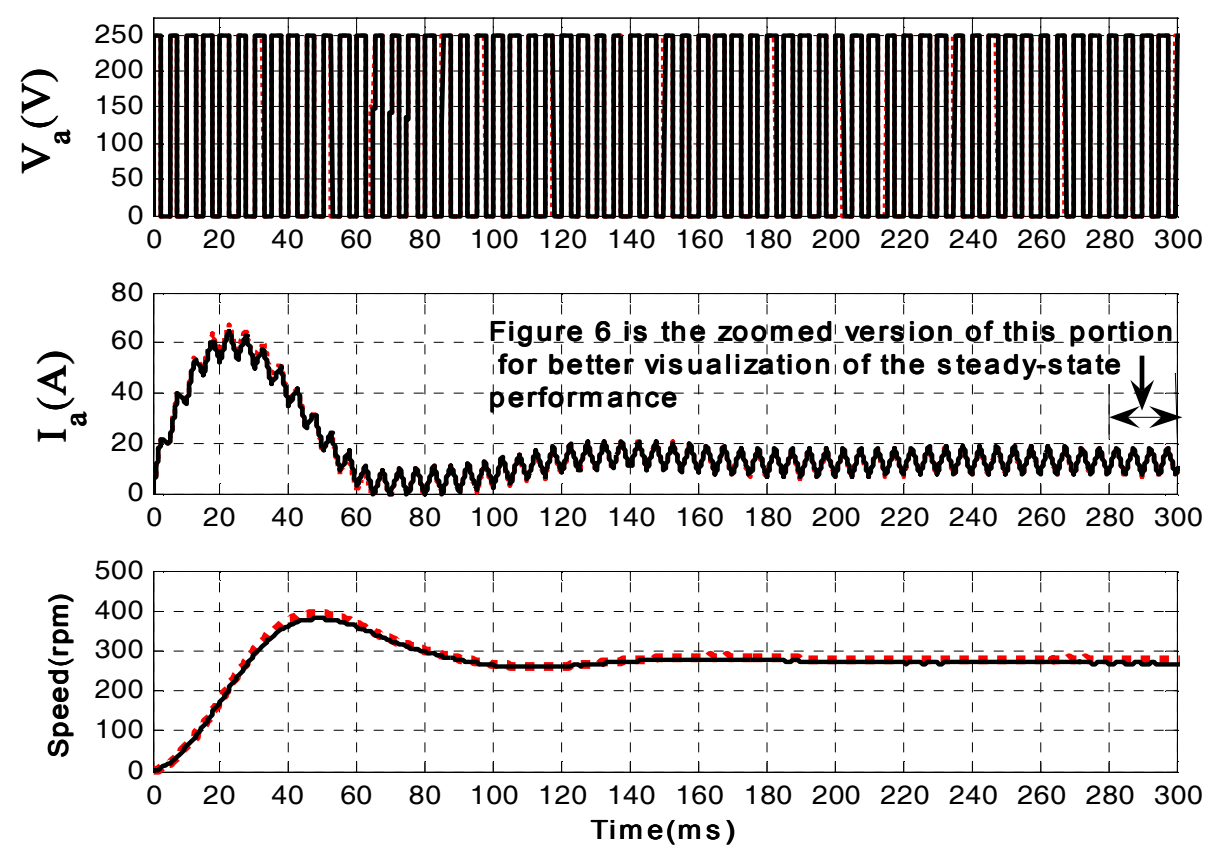

Figure 5. Transient response of the drive for continuous current operation

Computed using proposed algorithm

- - - - Computed using Runge-Kutta method 

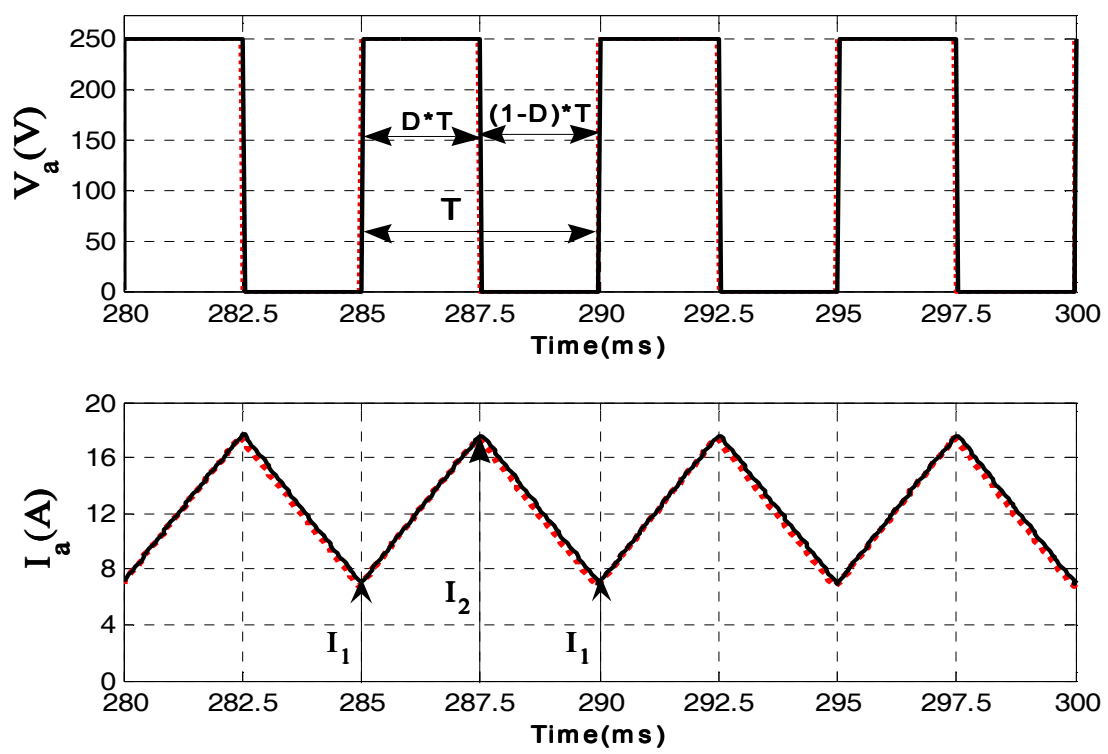

Figure 6 . Steady-state response of the drive for continuous current operation

Computed using algorithm given in this paper

Computed using Runge-Kutta method

The algorithm given above is applied to a separately excited dc motor drive which is powered from a chopper circuit and drives a fan type load. Chopper frequency of the chopper is chosen as $200 \mathrm{~Hz}$ and the input voltage as $250 \mathrm{~V}$. The parameters of the motor are : $\mathrm{Ra}=0.465 \Omega, \mathrm{La}=28 \mathrm{mH}, \mathrm{k} \Phi=4.0818 \mathrm{~V} \mathrm{sec} \mathrm{rad}^{-1}$ and $\mathrm{J}=0.165 \mathrm{~kg}-\mathrm{m}^{2}$. For the continuous current operation the load torque constant $\mathrm{k}_{\mathrm{L}}$ is chosen as $0.06 \mathrm{Nm}$ $\mathrm{sec}^{2} \mathrm{rad}^{-2}$, and it is chosen as $0.006 \mathrm{Nm} \mathrm{sec}^{2} \mathrm{rad}^{-2}$ for discontinuous current operation.

The transient and the steady state performance of the drive are computed by implementing the proposed algorithm, for $\mathrm{D}=0.5$ and continuous current operation case $\left(\mathrm{k}_{\mathrm{L}}=0.06 \mathrm{Nm} \mathrm{sec} \mathrm{rad}^{-2}\right)$, and they are illustrated in Figures 5 and 6 respectively. These figures also include the direct numerical solution of the state equations of the drive using fourth-order Runge-Kutta method [8]. The steady-state performance shown in Figure 6 is the zoomed version of the transient solution from $t=280 \mathrm{~ms}$ to $t=300 \mathrm{~ms}$, as shown in Figure 5, where the transient solution completely converges to its steadystate regime. From these figures it can be seen that the given algorithm gives excellent results, which are very close to the exact solution of the drive state-space equations obtained using Runge-Kutta's fourth-order method 

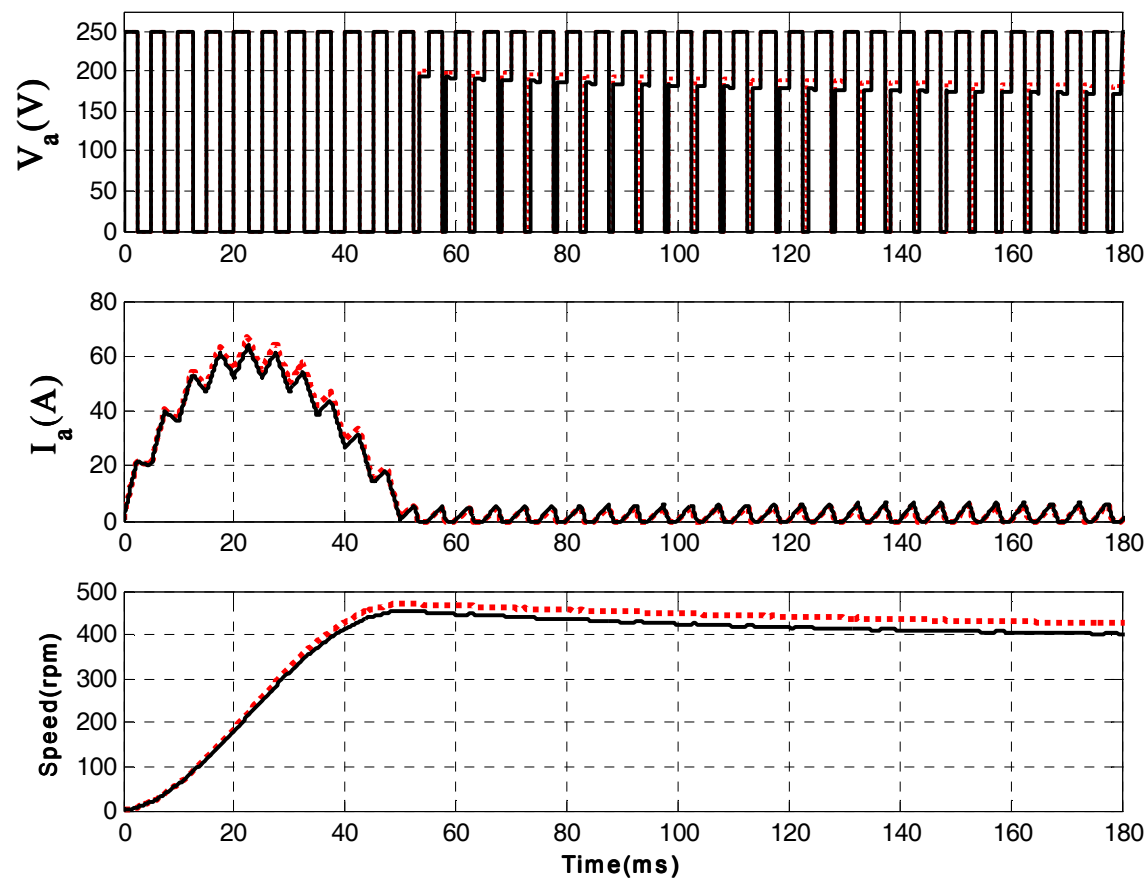

Figure 7. Transient response of the drive for discontinuous current operation

— Computed using proposed algorithm

_ _ _ - Computed using Runge-Kutta method
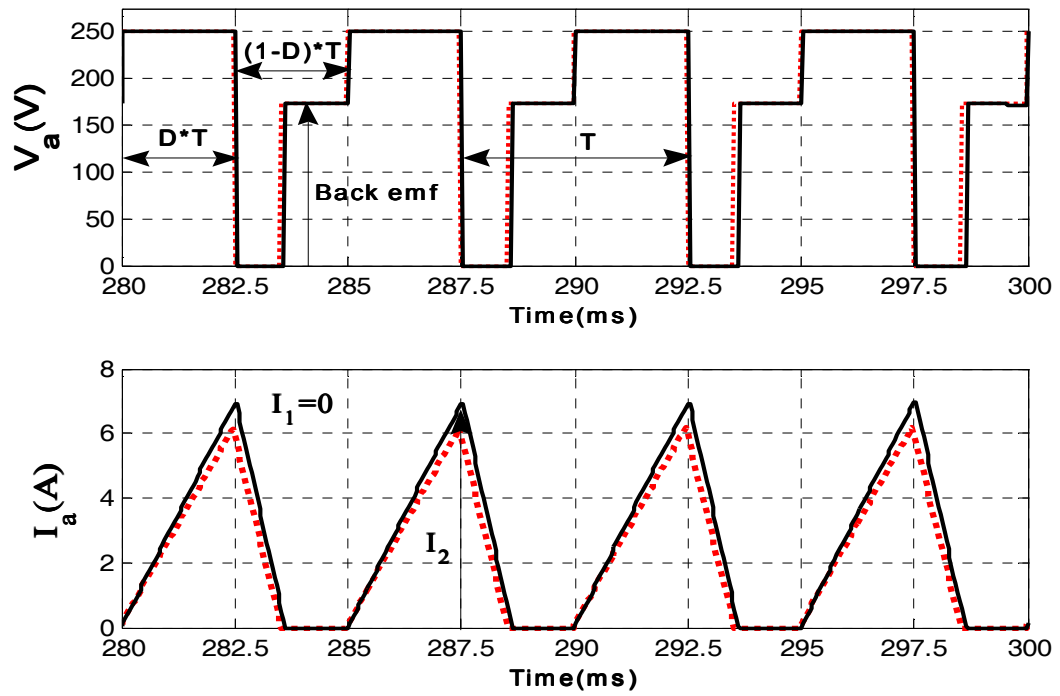

Figure 8. Steady-state response of the drive for discontinuous current operation

Computed using proposed algorithm

Computed using Runge-Kutta method 
For further verification of the accuracy of the given algorithm, the transient and steady state performance of the drive is obtained for discontinuous current operation case with again $\mathrm{D}=0.5$ and $\mathrm{k}_{\mathrm{L}}=0.006 \mathrm{Nm} \mathrm{sec} \mathrm{rad}^{-2}$, results are illustrated in figures 7 and 8 respectively. Although the transient performance is computed for $\mathrm{t}=300 \mathrm{~ms}$, in order to be able to see the effect of discontinuity clearly, plots are show up to $t=180 \mathrm{~ms}$ only. These figures also include the direct numerical solution of the state-space equations of the drive using fourth-order Runge-Kutta method. Examination of these figures show again that the proposed algorithm, besides its very simple structure and much less computing time, gives excellent results, as resulting response closely follows the results obtained from the application of Runge-Kutta fourth-order method.

The authors of reference [5] have mentioned in their paper that their method can be extended to chopper-controlled drives such as the ones mentioned in reference [10]. The authors of this current paper have made an attempt to verify the validity of the claims made in [5]. It was found that there is no possibility of extending the method of [5] to electrical drives hence the claims raised in that paper is baseless.

\section{CONCLUDING REMARKS}

A simple, practical and yet very accurate algorithm is proposed for computing transient as well as steady-state performance of chopper-controlled passive (R-L) and active (DC drive) loads. With this algorithm there is no need for Laplace and inverse Laplace transforms of the circuit differential equations as proposed in [5], nor for the knowledge of any numerical differential equation solving techniques. The algorithm is first applied to evaluation of the transient and steady-state performance of a series connected R-L load. Results are compared with the detailed numerical solution of the circuit differential equation using fourth-order Runge-Kutta method and excellent agreement is obtained between the two. The algorithm is further extended for computing the performance of a DC drive, both for continuous and discontinuous current operating modes. Again results obtained from the proposed algorithm are compared with the results obtained from the detailed solution of the drive differential equations using fourth-order Runge-Kutta method and excellent agreement is obtained between the two solutions. These results confirm the validity and accuracy of the proposed algorithm. To accomplish such a task by extending the method given in [5] will be near to impossible. It is believed that the proposed algorithm will be very useful for fast, easy and accurate computation of the transient as well as steady-state performance of chopper controlled loads and it can be easily extended for different types of forcing functions (different types of input voltage).

\section{Nomenclature}

$\mathrm{R}_{\mathrm{a}}, \mathrm{L}_{\mathrm{a}}$ : $\quad$ Armature winding resistance and inductance respectively

$\tau_{\mathrm{m}}: \quad$ Armature winding time constant $\left(\mathrm{L}_{\mathrm{a}} / \mathrm{R}_{\mathrm{a}}\right)(\mathrm{sec})$ 


\begin{tabular}{|c|c|c|}
\hline $\mathrm{k}_{\Phi}$ & : & Motor back emf constant $(\mathrm{Nm} / \mathrm{A}$ or $\mathrm{V} / \mathrm{rad} / \mathrm{sec})$ \\
\hline $\mathrm{J}$ & : & Combined load and motor inertia $\left(\mathrm{kg} / \mathrm{m}^{2}\right)$ \\
\hline $\mathrm{k}_{\mathrm{L}}$ & : & Load torque constant $\left(\mathrm{Nm} \mathrm{sec} / \mathrm{rad}^{2}\right)$ \\
\hline $\mathrm{f}$ & : & Chopper frequency (Hz.) \\
\hline $\mathrm{V}_{\mathrm{s}}$ & : & Chopper supply voltage (V) \\
\hline $\mathrm{T}$ & $:$ & Chopper period $(=1 / \mathrm{f})(\mathrm{sec})$ \\
\hline$t_{\text {on }}$ & : & Chopper on period $(\mathrm{sec})$ \\
\hline$t_{\text {off }}$ & : & Chopper off period $\left(t_{o f f}=(1-\mathrm{D}) \mathrm{T}\right)(\mathrm{sec})$ \\
\hline $\mathrm{D}$ & $:$ & Chopper duty cycle $\left(=t_{o n} / \mathrm{T}\right)$ \\
\hline$V_{a}$ or & $\mathrm{V}_{\text {motor: }}$ & Voltage across the motor armature (V) \\
\hline $\mathrm{H}$ & $:$ & Computation step size (sec) \\
\hline$i_{a(n)}$ & : & Current (motor armature) at $\mathrm{n}^{\text {th }}$ computation step (A) \\
\hline$i_{a(n-1)}$ & : & Current (motor armature) at (n-1)th computation step (A) \\
\hline$\omega$ & $:$ & Motor speed (rad/sec) \\
\hline$\omega_{\mathrm{n}}$ & : & Motor speed at $\mathrm{n}$-th computation step $(\mathrm{rad} / \mathrm{sec})$ \\
\hline$\omega_{n-1}$ & : & Motor speed at (n-1)th computation step ( $\mathrm{rad} / \mathrm{sec})$ \\
\hline
\end{tabular}

\section{REFERENCES}

1. L. W. Nagel, SPICE2: A computer program to simulate semiconductor circuits, Memorandum No: UCB/ERL M520, Electric Research Laboratory, College of Engineering, University of California, Berkeley, CA, May 9, 1975.

2. Electromagnetic Transient Program (EMTP) Application Guide, EPRI Report No: EL-460, Project 2149-1, Westinghouse Electric Corp., Pittsburgh, PA, 1986.

3. D. Hanselman and B. Littlefield, Mastering MATLAB, Prentice Hall, 1996.

4. The MathWorks Inc. The student edition of SIMULINK, users guide, Prentice Hall, Englewood Cliffs, NJ, 1996.

5. S. U. Ahmed and A. A. Khan, Use of superposition technique for determining Laplace inverse transform of a function involving square wave periodic variations and its applications, Electric Power Components and Systems 33, 745-753, 2005.

6. M. H. Rashid, Power Electronics, Circuits, Devices and Applications, third edition, Pearson, Prentice Hall, 2004.

7. S. B. Dewan and A. Straughen, Power Semiconductor Circuits, John Wiley \& Sons, 1975.

8. S. C. Chapra and R. P. Canale, Numerical Methods for Engineers, fifth edition, McGraw-Hill, 2006.

9. M. Akbaba and S.Q. Fakhro, New model for single-unit representation of induction motor loads, including skin effect, for power systems transient stability studies IEE Proc., Part B, Electric Power Applications, 139, 521-533, 1992.

10. D.R. Kohli and S.U. Ahmed, Performance of chopper controlled DC drive with elastic coupling and periodically varying load torque, IEEE Trans. On Industry Applications IA-18, 712-727, 1982. 